\title{
Assessing the Hardness of Quenched Medium Steel Using an Ultrasonic Nondestructive Method
}

\author{
Shao-Yi Hsia ${ }^{1}$ and Yu-Tuan Chou $^{2}$ \\ ${ }^{1}$ Department of Mechanical \& Automation Engineering, Kao Yuan University, Kaohsiung 821, Taiwan \\ ${ }^{2}$ Department of Applied Geoinformatics, Chia Nan University of Pharmacy \& Science, Tainan 717, Taiwan \\ Correspondence should be addressed to Yu-Tuan Chou; ytchou@mail.chna.edu.tw
}

Received 23 September 2014; Accepted 24 November 2014

Academic Editor: Fernando Lusquiños

Copyright (C) 2015 S.-Y. Hsia and Y.-T. Chou. This is an open access article distributed under the Creative Commons Attribution License, which permits unrestricted use, distribution, and reproduction in any medium, provided the original work is properly cited.

\begin{abstract}
Developing new materials or improving their heat treatment techniques is key to industrial upgrades for increasing fastener product quality. Nowadays, high tensile strength bolts are heat-treated to achieve desired mechanical properties such as hardness, strength, toughness, and resistance to fatigue and wear. Ultrasound detection is one widely used nondestructive inspection technique. Based on the characteristics of wave transmission, the refraction, diffraction, and scattering of ultrasound wave velocity and attenuation in a material are governed by its grain boundary characteristics. In this study, $\mathrm{C} 1045$ middle carbon steel was heat-treated at various temperatures and then water-quenched, and the relationships among grain size, ultrasonic velocity, attenuation, and material hardness were then determined using two ultrasound sources. Our experimental results show that a smaller average grain size as well as higher hardness can be obtained from higher quenching temperatures. Faster acoustic velocities and slower attenuation coefficients are caused by higher material hardness. A scattering effect is more obvious for higher transducer frequencies. Our results demonstrate another nondestructive test that can assess the quenching process in the fastener industry.
\end{abstract}

\section{Introduction}

Fasteners $[1,2]$ are broadly used essential parts of machinery, civil engineering projects, building construction, electronics, electric machines, automobiles, and aerospace industries. Fastener manufacturers in Taiwan are constantly developing fasteners with advanced technology and added value, which are required for higher precision and strength. For example, high-strength bolts require heat treatment to achieve expected properties like hardness, strength, toughness, fatigue resistance, and wear resistance. Inspection methods are also needed for quality assurance.

Mechanical properties such as yield strength, fatigue strength, and creep are highly dependent on grain size. The metallographic method is generally used for judging grain size, but it destroys the specimen. Ultrasonic methods use the attenuation and back reflection of sound waves to evaluate grain size. Attenuation is the difference between the amplitudes of the two echoes from two parallel surfaces of a sample. The attenuation coefficient is correlated to grain size. Burkle [3] proposed the experimental procedure for attenuation. Kopec and Hanak [4] studied the relationship between the grain size of railway axle material and ultrasonic attenuation and regarded grain size as the major factor in the ultrasonic attenuation of Rayleigh scattering. Ambardar et al. [5] measured the relationship between the ultrasonic attenuation coefficient and porosity rate, pore diameter, grain size, and probe frequency in copper aluminum alloy casting and found that the attenuation coefficient increased with increasing porosity rate, grain diameter, and probe frequency but decreased with increasing pore diameter. Smith [6] studied the relationships between ultrasonic attenuation and grain size and grain size distribution and found that identical average grain size but different size distribution caused the attenuation-frequency curve to be distinct and to not correspond to the grain size distribution from a specific curve. Nicoletti and Anderson [7] used a theoretical analysis of attenuation to estimate the regularity of grain size distribution. Lott and Malik [8] and Wang et al. [9] investigated the effects on ultrasonic attenuation from austenitic stainless steel welding, the heat-affected zone, and micrograin structure changes of the base material. Sarpun et al. [10] utilized 
ultrasound to test the relationship between marble grain size and wave velocity. Sarpün and Kiliçkaya [11] used ultrasound for testing the relationship between marble grain size and ultrasonic attenuation. Bouda et al. [12] experimented on the heat treatment of steel and observed the effects of grain size on the velocity of sound and attenuation rate and concluded that the velocity of sound was inversely proportional to grain size and the ultrasonic attenuation rate was not suitable for evaluating steel grain size because of its large variance.

Ahn et al. [13] evaluated the yield strength and grain size of low-carbon steel with ultrasound and concluded that the ultrasonic attenuation rate was directly proportional to grain size with an ultrasonic frequency of $5 \mathrm{MHz}$, the ultrasonic attenuation rate was inversely proportional to yield strength, the yield strength error of the predicted ultrasonic attenuation rate appeared to be $\pm 50 \mathrm{MPa}$, and the yield strength error of the material predicted by the velocity of sound was too large to be suitable.

Although several researchers have applied ultrasound to steel testing, there are no published studies on the relationships between ultrasonic properties and grain hardness under different heat treatments. Most of the current examinations of quenching processes in the fastener industry have merely examined hardness without metallographic analyses, and some have not even measured quenching hardness. This study attempted to change the microstructure of C1045 carbon steel with various quenching temperatures and used ultrasonic probes at distinct frequencies $(10 \mathrm{MHz}$ and $5 \mathrm{MHz}$ ) to observe the relationships among ultrasonic wave velocity, attenuation rate, grain size, and hardness under various quenching temperatures. Our results are expected to provide fastener manufacturers with an alternative nondestructive test of the heat treatment process for the purpose of maintaining product quality.

\section{Theory}

2.1. Ultrasound Characteristics. The audible range of acoustic waves depends on their frequencies and the audible frequencies of the human ear, which is between $20 \mathrm{~Hz}$ and $20 \mathrm{kHz}$. Acoustic waves cannot be heard by humans when their frequencies are higher than that range (ultrasound). Ultrasound can be generated by the compression and vibration of a piezoelectric crystal such as lead zirconate titanate (PZT) in an ultrasonic probe resulting from thickness changes caused by positive/negative voltage signals. Ultrasound is widely applied to nondestructive testing techniques and was rapidly developed because of its

(1) shorter wave length (the higher the frequency, the shorter the wave length) and high directional characteristics of sound beams,

(2) favorable penetrability and propagation characteristics,

(3) strong reflection characteristics,

(4) ease of transformation into various waveforms through waveform conversion.
The transmission velocity of sound in a substance is called the velocity of sound. The velocity of sound with a given wavelength in a substance approaches a constant value that changes with different wave lengths. Generally speaking, the velocity of longitudinal sound waves is twice that of transverse waves in homogeneous substances (about $1.8 \mathrm{x}$ in steel), and surface wave velocity is slightly less than transverse waves (about $0.92 \mathrm{x}$ of transverse waves in steel). Ultrasonic frequency refers to the number of vibrations of substance particles per second, with the vibration frequencies of all particles in the same wave being identical. Wave length is the distance between two neighboring planes with the same wave phase; that is, the longitudinal wave length is the distance between two congestion areas or two thin areas, while the transverse wave length is the distance between two neighboring wave crests or wave troughs. The mathematical relationship among the velocity of sound $(V)$, frequency $(f)$, and wave length $(\lambda)$ is shown in

$$
V=f \times \lambda
$$

The velocity of various sound waves in a substance approaches a constant value. According to (1), higher ultrasonic frequencies have inversely shorter wave lengths. The velocity of ultrasound in a solid can be calculated with

$$
V=\frac{2 X}{t}
$$

where $X$ is the thickness of the test piece $(\mathrm{m})$ and $t$ is ultrasonic transmission time (s).

The space that is influenced by the ultrasonic sound effect is called the acoustic field. The strongest sound pressure point that is the most distant from the piezoelectric crystal is regarded as the cut-off point, and the area to the left of it is called the near field while the far field is to the right. Ultrasonic interference is most apparent in the near field, while the sound pressure curve becomes short and wide with increasing distance in the far field; that is, sound pressure on the centerline is inversely proportional to distance. Divergence and attenuation are two factors in the attenuation of ultrasonic strength.

(1) Divergence is the angle that a sound beam makes as it spreads outward with distance from the piezoelectric crystal and accompanies a decrease in sound strength.

(2) Two attenuation properties, absorption and scattering, are considered to evaluate a material's geometry and imperfections. Absorption is the conversion of sound energy to thermal energy, and it is through scattering that sound strength is reduced. Scattering is due to nonhomogeneities (such as impurities, air bubbles, and grain boundaries) in the material that create obstacles to the transmission of sound and results in various components of sound being weakened.

Ultrasonic strength would present an exponential functional attenuation with increasing distance:

$$
J=J_{0} \exp (-\alpha X),
$$


where $J_{0}$ is the original ultrasonic strength, $J$ is the attenuated ultrasonic strength, and $\alpha$ is the attenuation coefficient. An attenuation coefficient is used to quantitatively present ultrasonic strength attenuation, which is related to the material and its internal structure.

2.2. Heat Treatment of Carbon Steel. Heat treatment is the process of controlling heat and cold to change the structure of a solid metal or alloy in order to give it desired properties and states. Heat treatment transformation refers to the changes in the microstructure of a solid, called phase transformation. The speed of heating (i.e., rapid or slow) normally does not change the transformation; however, the cooling process changes it a lot. In other words, most heat treatment is determined by cooling; for example, continuous cooling transformation (CCT) and isothermal transformation (TTT). The common heat treatment for steel includes annealing, normalizing, quenching, and tempering, each of which has distinct objectives and uses.

2.3. Metallographic Examination. Metallography is the study of the internal structures of metals and alloys using microscopes. Metallography, which is generally similar to metallurgy, mainly is the study of internal structural changes in metals and alloys caused by chemical composition, condensation, calendering, welding, and heat treatment and their effects on the physical, chemical, and mechanical properties of those materials. With emerging new materials, metallography does not simply study metals and alloys, but also presents significant implications for materials assessment and defect analyses. The optical microscope (OM) is used in metallographic testing, utilizing visible light focused on and reflected from the observed surface, and magnifying it with an objective and eyepiece for naked-eye observation or camera recording, or displays images on a screen with acquisition software. Optical microscopes are used for metallographic observations; that is, to observe grain boundaries and microstructures following chemical etching of the sample. Chemical etching is not needed during failure analysis to observe crack/inclusion position, distribution, shape, and direction.

2.4. Grain Size Testing [14]. Grain size is normally evaluated or measured for length, area, volume, or grain size level. The grain size presented with the level of grain size has nothing to do with measuring methods and units of measurement. It can be subdivided as follows.

(1) Microlevel of grain size $(G)$. Under 100x, a $645.16 \mathrm{~mm}^{2}$ sample area contains the numbers of grains $(N)$ and $G$ as $N=2^{G-1}$.

(2) Macrolevel of grain size $\left(G_{m}\right)$. Under 1x, a $645.16 \mathrm{~mm}^{2}$ sample area includes the number of grains $(N)$ and $G_{m}$ as $N=2^{G_{m}-1}$.

There are three ways to measure grain size.

(1) Comparison-comparing a sample to a series of standard diagrams. When evaluating grain size with

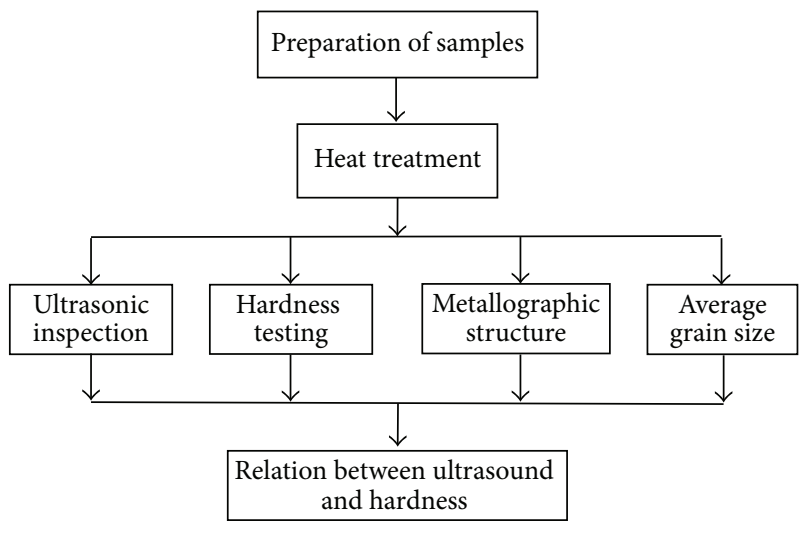

FIGURE 1: Flowchart of study.

the comparison method, the smallest error appears when grain appearance is similar to the standard diagram.

(2) Area-calculating the number of grains $(N)$ in a given area.

(3) Resection-calculating the number of resection points $(P)$ between the measuring lines or grid to a given length and grain boundary.

Any method for measuring grain size is initially presented with the number of grains in a unit area or the number of resection points on the grain boundary of a unit length. Such values are not as easily used as the normally employed parameters of average grain diameter, average intercept, average grain sectional area, and grain size level.

\section{Research Workflow and Methods}

3.1. Research Workflow. Machinery processed samples were divided into five groups (three pieces in each group) and treated with different quenching temperatures. The heattreated samples were then subjected to ultrasonic, Rockwell hardness, and metallographic examinations to observe structure and average grain size. Correlations among the various tests were then discussed. The procedure is depicted in Figure 1.

3.2. Experimental Method. Sampling rods were fabricated with a lathe to an outer diameter of $20 \mathrm{~mm}$ and length of $25 \mathrm{~mm}$ (Figure 2). The experimental equipment and procedures used were as follows.

(1) High-temperature oven:

(a) power was turned on and the required temperature was set;

(b) samples were placed in the oven and the door was locked; samples were heated for $20 \mathrm{~min}$ after the oven temperature rose to the designated testing temperature $\left(760^{\circ} \mathrm{C}\right)$;

(c) samples were then clamped to a bucket for water quenching; 


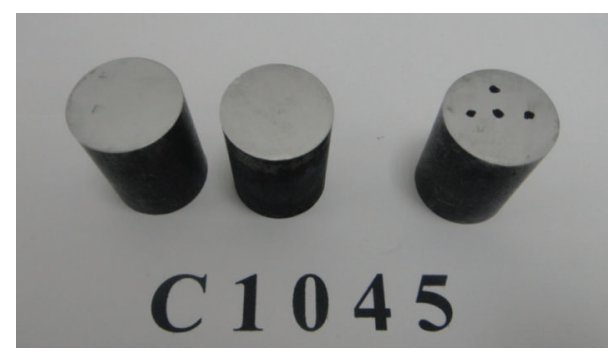

FIGURE 2: Three test pieces with the heat treatment temperature $760^{\circ} \mathrm{C}$ (the marked points at the right piece for the hardness testing).

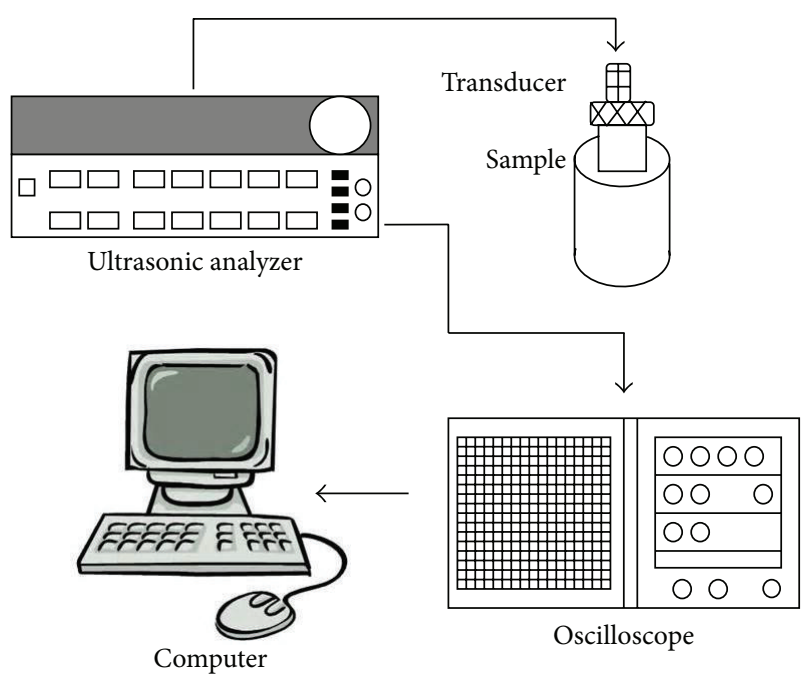

FIGURE 3: Layout of the ultrasonic experiment.

(d) samples were removed from the bucket after $1 \mathrm{~min}$;

(e) the above steps were followed for the other four heat treatments $\left(800^{\circ} \mathrm{C}, 840^{\circ} \mathrm{C}, 880^{\circ} \mathrm{C}\right.$, and $\left.920^{\circ} \mathrm{C}\right)$.

(2) Ultrasonic examination:

(a) a LeCroy Wave Surfer 422 oscilloscope and an Impulse Analyzer 5052 UAX 50 were used for ultrasonic testing; a transducer was attached to and transmitted ultrasound pulses into the test rod; pulses traveled through the samples, responded to their mechanical properties, and reflected back to the transducer (pulse-echo method) to be transformed back into electrical pulses that were observed with the oscilloscope; this method was used to determine the ultrasonic wave velocity or thickness of each specimen; Figure 3 shows the experimental setup;

(b) transducer frequencies were $5 \mathrm{MHz}$ and $10 \mathrm{MHz}$

(c) general low-viscosity motor oil was used as the coupling fluid.

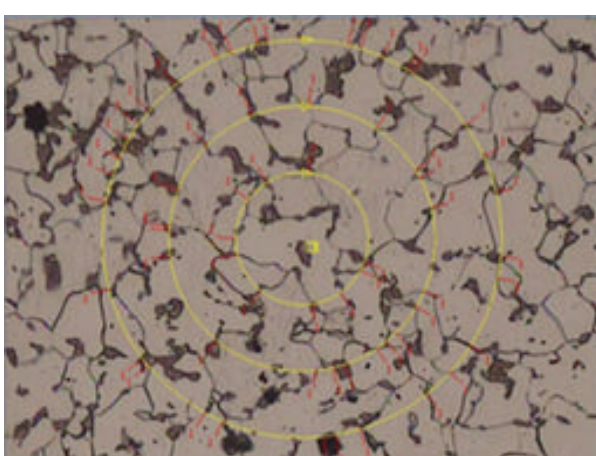

FIgURE 4: Circular Intercept is composed of a set of 3 concentric zones.

(3) Rockwell hardness testing (based on ISO 6508-1):

(a) a testing point was marked along a circle drawn from the rod's center out to half of its radius (Figure 2);

(b) sample hardness was measured in three places with the Rockwell hardness machine, and average hardness was calculated from three replicates; average replicate values were further used to calculate a total average for a given treatment.

(4) Grinding and polishing:

(a) sample surfaces were ground flat with a grinding machine using 320\# 2500\# aluminum oxide sandpaper, and a diamond suspension polishing machine was then used until no scratches remained;

(b) samples were etched with $3 \%$ nitric acid solution for $10 \mathrm{sec}$;

(c) samples were cleaned of the etching solution with water and blow-dried.

(5) Observation of metallographic structure:

(a) etched samples were examined with an optical microscope;

(b) an amplification factor of 200x was used for observing the metallographic structure and taking photographs of each test piece.

(6) Measurement of average grain size.

Circular Intercept was applied to this experiment. The 200x photographs of sample centers and surrounding metallographic microstructures show a set of three concentric zones (Figure 4). The total length of the three circumferences was $500 \mathrm{~mm}$; at least 50 cut-off points in the grids and observation zones were measured under magnification. When single circles were used, circumferences were $<250 \mathrm{~mm}$ and there were $\geq 25$ cut-off points. Five different positions on the test piece were selected for measurement and the acquired data was calculated as the average crystallinity of the samples. 
TABLE 1: Hardness along the circle of $1 / 2$ radius and center of the samples with different temperatures.

\begin{tabular}{|c|c|c|c|c|c|c|c|c|c|c|}
\hline \multirow{2}{*}{ Temperature $\left({ }^{\circ} \mathrm{C}\right)$} & \multicolumn{2}{|c|}{760} & \multicolumn{2}{|c|}{800} & \multicolumn{2}{|c|}{840} & \multicolumn{2}{|c|}{880} & \multicolumn{2}{|c|}{920} \\
\hline & Average & Center & Average & Center & Average & Center & Average & Center & Average & Center \\
\hline Hardness (HRC) & 20.08 & 19.77 & 24.36 & 23.33 & 32.78 & 29.00 & 42.44 & 41.60 & 44.29 & 43.37 \\
\hline Difference (\%) & \multicolumn{2}{|c|}{1.54} & \multicolumn{2}{|c|}{4.22} & \multicolumn{2}{|c|}{11.52} & \multicolumn{2}{|c|}{1.97} & \multicolumn{2}{|c|}{2.08} \\
\hline
\end{tabular}

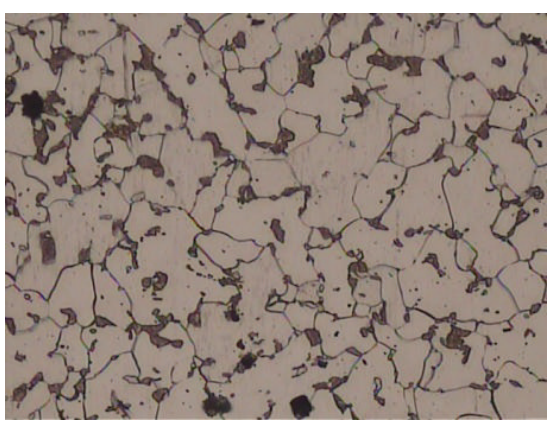

(a) $760^{\circ} \mathrm{C}$

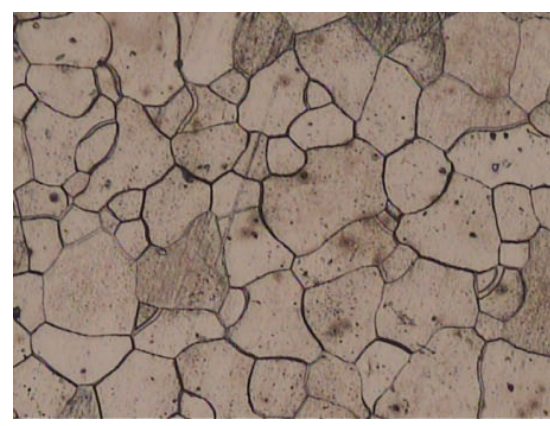

(b) $840^{\circ} \mathrm{C}$

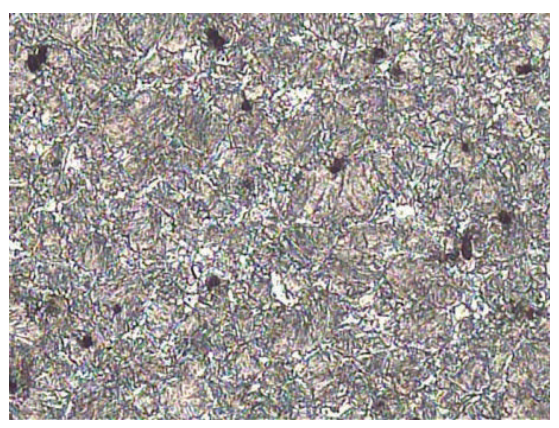

(c) $920^{\circ} \mathrm{C}$

FIGURE 5: Three different metallographic structures with different temperatures after water quenching.

\section{Results and Discussion}

4.1. Rockwell Hardness Testing. A Rockwell hardness machine was utilized for testing the samples with heat treatment temperatures of $760^{\circ} \mathrm{C}, 800^{\circ} \mathrm{C}, 840^{\circ} \mathrm{C}, 880^{\circ} \mathrm{C}$, and $920^{\circ} \mathrm{C}$ (Table 1). The average hardness values in here were calculated from the testing points marked along a circle drawn from the rod's center out to half of its radius (Figure 2). Higher temperatures imparted higher average hardness values after water quenching. Moreover, the average hardness of the sample does not appear to be largely different, revealing that the $20 \mathrm{~mm}$ diameter test piece was not obviously affected by the mass effect.

4.2. Metallographic Structure and Average Grain Size. An optical microscope was used for metallographic testing of the samples. Figure 5(a) presents the ferrite (white) and pearlite (black) annealing structures that appeared after the $760^{\circ} \mathrm{C}$ heat treatment, and pearlite with incomplete solid solution was also found in the ferrite base. According to the ironcarbon equilibrium diagram, a heating temperature of $760^{\circ} \mathrm{C}$ does not reach the austenitic temperature $\left(T_{A}\right)$ of 1045 carbon steel, but merely appears in the annealing temperature range. Figure 5(b) shows that ferrite (white) and crude pearlite (black) did not present the martensite structure, possibly because of delayed quenching and an insufficient reduction in cooling speed. Figure 5(c) reveals martensite that occurred with transformation in the mixed structure of pearlite and residual austenite.

When integrating an optical microscope with Circular Intercept, average grain size measured by metallographic Circular Intercept was transformed by an amplification factor of 100x, based on a comparison with grain-size level number [14]. Furthermore, the relationships of random orientation and isometric grains were used to calculate average grain size via interpolation. The average grain size of the quenched

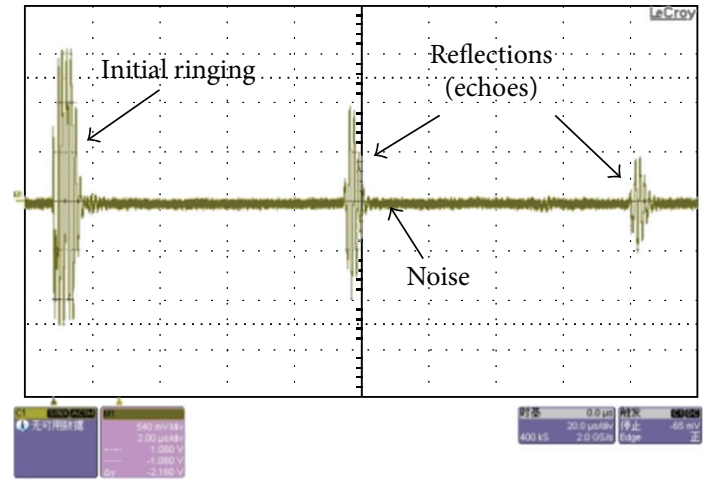

FIGURE 6: Response of ultrasound in a sample with heat treatment $760^{\circ} \mathrm{C}$ and $5 \mathrm{MHz}$. Scattered waves appear as noise superimposed on the multiple front and back echoes.

structures experiencing $880^{\circ} \mathrm{C}$ and $920^{\circ} \mathrm{C}$ treatments appears refinement (Table 2). Pure iron transformation data indicate that the samples present an austenitic transformation at those two temperatures, the grains recrystallize into smaller grains, and martensite still remains in the austenitizing phase after water quenching. In this case, the measured average grain sizes present a certain refinement in comparison to the other three test temperatures $\left(760^{\circ} \mathrm{C}, 800^{\circ} \mathrm{C}\right.$, and $\left.840^{\circ} \mathrm{C}\right)$.

4.3. Ultrasonic Testing. Transducers with frequencies of 5 and $10 \mathrm{MHz}$ were utilized for testing samples treated with temperatures of $760^{\circ} \mathrm{C}, 800^{\circ} \mathrm{C}, 840^{\circ} \mathrm{C}, 880^{\circ} \mathrm{C}$, and $920^{\circ} \mathrm{C}$. Figure 6 shows the time-domain plot of echo signals in the $760^{\circ} \mathrm{C}$ test pieces at a transducer frequency of $5 \mathrm{MHz}$. Figure 7 presents the time-domain plot of echo signals in the $760^{\circ} \mathrm{C}$ test pieces at a transducer frequency $10 \mathrm{MHz}$. These figures show that the three waveforms were the initial ringing and first and second echoes of ultrasounds being transmitting between the two 
TABLE 2: Grain-size number and average grain size with different temperatures.

\begin{tabular}{lccccc}
\hline Temperature $\left({ }^{\circ} \mathrm{C}\right)$ & 760 & 800 & 840 & 880 & 920 \\
\hline Grain-size number $(200 \mathrm{x})$ & 10.7 & 10.1 & 10.6 & 12.1 & 12.4 \\
\hline Grain-size number $(100 \mathrm{x})$ & 8.7 & 8.1 & 8.6 & 10.1 & \\
\hline Average grain size $(\mathrm{mm})$ & 0.0177 & 0.0218 & 0.0183 & 0.0108 & 0.0105 \\
\hline
\end{tabular}

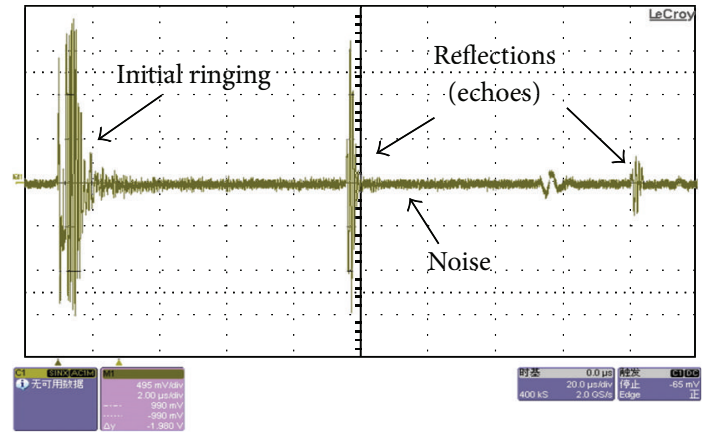

FIGURE 7: Response of ultrasound in a sample with heat treatment $760^{\circ} \mathrm{C}$ and $10 \mathrm{MHz}$. Scattered waves appear as noise superimposed on the multiple front and back echoes.

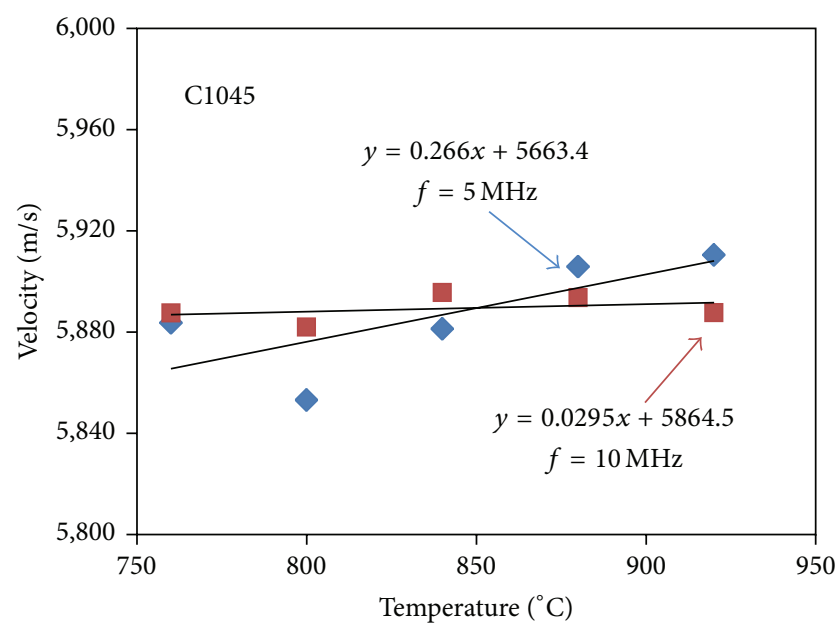

FIGURE 8: Velocity of samples at different heat treatment temperatures using 5 and $10 \mathrm{MHz}$.

parallel interfaces of the test piece. As ultrasound is gradually attenuated in the transmission medium, the amplitudes of the first and second echoes were less than the initial ringing and the decrease was used to calculate the attenuation coefficient of the test piece with the attenuation equation. What is more, waveforms with high-frequency echoes were more complex than those with low-frequency echoes because the shorter wave length of high-frequency ultrasound was affected by grain boundary and because more scattering echoes are received by the transducer.

Round-trip times from first to third echo signals (Figures 6 and 7) were calculated. The ultrasonic wave velocity in the test piece was calculated by using the thickness of the test piece in (2). Figure 8 shows the 5 and $10 \mathrm{MHz}$ wave

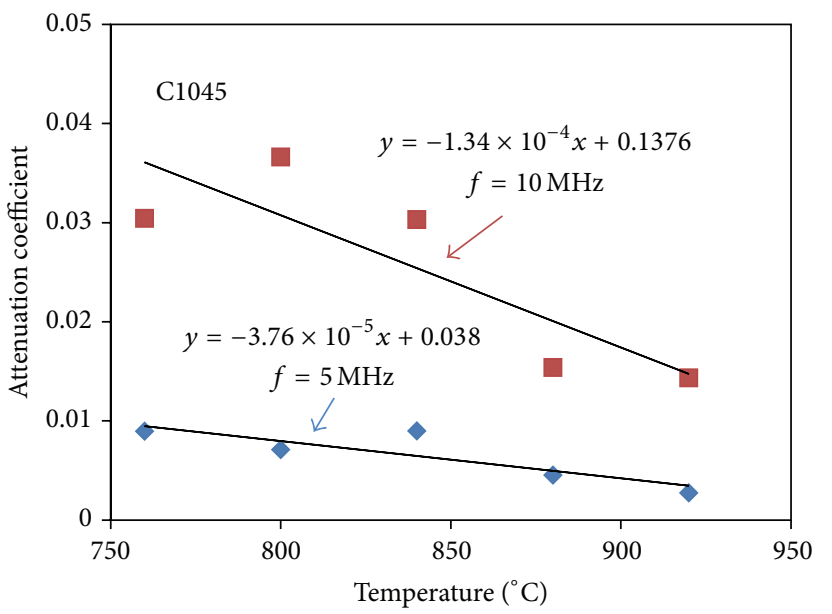

Figure 9: Attenuation coefficients of samples at different heat treatment temperatures using 5 and $10 \mathrm{MHz}$.

velocity responses to different heat treatments. Wave velocity at $5 \mathrm{MHz}$ increased with increasing treatment temperature, with the lowest average wave velocity being $5853.07 \mathrm{~m} / \mathrm{sec}$ at $800^{\circ} \mathrm{C}$ and the highest being $5910.40 \mathrm{~m} / \mathrm{sec}$ at $920^{\circ} \mathrm{C}$, the difference being $0.98 \%$. The changes at $10 \mathrm{MHz}$ were milder, with the lowest average wave velocity being $5881.89 \mathrm{~m} / \mathrm{sec}$ at $800^{\circ} \mathrm{C}$ and the highest being $5895.54 \mathrm{~m} / \mathrm{sec}$ at $840^{\circ} \mathrm{C}$, a difference of only $0.23 \%$. Therefore, there were greater effects at a wave velocity of $5 \mathrm{MHz}$ than at $10 \mathrm{MHz}$. The regressive trend-line reveals that the former had a slope of 0.266 and the latter 0.0295 . As a result, $5 \mathrm{MHz}$ appears to be more sensitive than $10 \mathrm{MHz}$ for nondestructive testing of heat treatments when using ultrasonic wave velocity as the measuring datum.

When calculating the amplitude ratios of the three echo signals, echo attenuation under different heat treatments and ultrasound frequencies was calculated with (3). Figure 9 indicates the attenuation responses at 5 and $10 \mathrm{MHz}$ during different heat treatment temperatures. There was an increasing trend in the attenuation coefficient with increasing average grain size (from high temperature to low temperature) at $5 \mathrm{MHz}$, with the lowest average attenuation being 0.0027 at $920^{\circ} \mathrm{C}$ and the highest being 0.0090 at $760^{\circ} \mathrm{C}$ and $840^{\circ} \mathrm{C}$. Attenuation at $10 \mathrm{MHz}$ revealed the same trend but was more obvious, with the lowest average attenuation being 0.0143 at $920^{\circ} \mathrm{C}$ and the highest being 0.0366 at $800^{\circ} \mathrm{C}$. It is possible that scattering was more apparent because a higher frequency transducer was used for this experiment. In the common frequency range for materials testing, grain size is smaller than the wave length so random scattering replaces geometric scattering, similar to headlight scattering in a fog. Grain size 
TABLE 3: Relation of wave length and average grain size with different temperatures.

\begin{tabular}{|c|c|c|c|c|c|}
\hline Temperature $\left({ }^{\circ} \mathrm{C}\right)$ & 760 & 800 & 840 & 880 & 920 \\
\hline Wave length $(5 \mathrm{MHz}, \mathrm{m})$ & 1.174 & 1.178 & 1.179 & 1.182 & 1.176 \\
\hline Wave length $(10 \mathrm{MHz}, \mathrm{m})$ & 0.589 & 0.588 & 0.590 & 0.588 & 0.588 \\
\hline $\begin{array}{l}\text { Average grain size/wave length } \\
(5 \mathrm{MHz}, \%)\end{array}$ & 1.5 & 1.9 & 1.6 & 0.9 & 0.9 \\
\hline $\begin{array}{l}\text { Average grain size/wave length } \\
(10 \mathrm{MHz}, \%)\end{array}$ & 3.0 & 3.7 & 3.1 & 1.8 & 1.8 \\
\hline
\end{tabular}

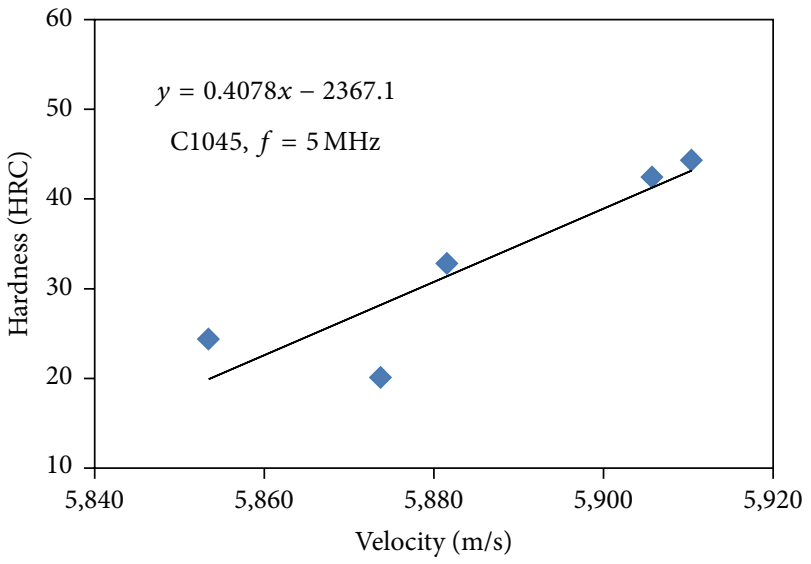

FIGURE 10: Relationship of velocity and hardness at different heat treatment temperatures using $5 \mathrm{MHz}$.

is about $0.001-0.01$ times the wave length, so scattering is not a critical factor in real applications. However, scattering presents a rapid (cubed) increase with grain size, making scattering obvious when the grain is 0.1-1.0 times the wave length. With common transducer frequencies, average grain size and wave length proportions are about $0.001-0.01$ times the wave length. Table 3 shows the relationship between the average size of the test piece and wave length with varying frequencies after heat treatment. The average grain size and wave length proportion at $10 \mathrm{MHz}$ was twice as large as with $5 \mathrm{MHz}$ at each heat treatment. Consequently, measurements taken with the $10 \mathrm{MHz}$ transducer made the attenuation more obvious because of scattering. The regressive trend-lines in Figure 9 reveal that the slope was $-3.76 \times 10^{-5}$ at $5 \mathrm{MHz}$ and $-1.34 \times 10^{-4}$ at $10 \mathrm{MHz}$. In this case, $10 \mathrm{MHz}$ appeared to be more sensitive than $5 \mathrm{MHz}$ when taking ultrasonic attenuation as the measuring datum.

Using the ultrasound for measuring the hardness of C1045 carbon steel can refer to the relationship between wave velocity and hardness at an ultrasonic frequency of $5 \mathrm{MHz}$ (Figure 10) and the relationship between the attenuation coefficient and hardness with the ultrasonic frequency $10 \mathrm{MHz}$ (Figure 11). Figure 10 presents the positive correlations between wave velocity and hardness; that is, hardness increased with increasing wave velocity. However, the experiment revealed a worse inosculating effect at $760^{\circ} \mathrm{C}$. Figure 11 shows negative correlations between attenuation coefficient and hardness; that is, material hardness decreased

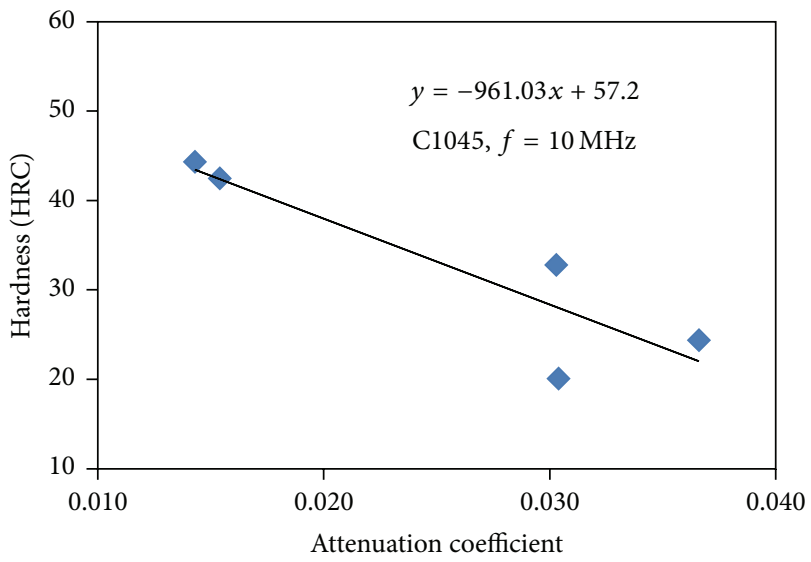

FIGURE 11: Relationship of attenuation coefficient and hardness at different heat treatment temperatures using $10 \mathrm{MHz}$.

with an increasing attenuation coefficient. The wave velocity or attenuation coefficient suitable for use in measuring hardness is the most significant finding of this study. The hardness values determined from velocity at the lowest $\left(760^{\circ} \mathrm{C}\right)$ and highest $\left(920^{\circ} \mathrm{C}\right)$ experimental temperatures for C1045 carbon steel appeared to have a difference of $0.75 \%$, based on $5 \mathrm{MHz}$ transducer measurements (Figure 10). When hardness was determined from the attenuation coefficient derived via the $10 \mathrm{MHz}$ transducer, the difference was $1.50 \%$. As a consequence, the error within a small measuring range would be less than the wave velocity measurement when estimating hardness with an attenuation coefficient.

\section{Conclusions}

C1045 carbon steel test pieces were heated to different temperatures and then water-quenched. Nondestructive testing (at frequencies of 10 and $5 \mathrm{MHz}$ ) and destructive testing (metallography and hardness) were used for observing changes in the structure and grain size of the steel at various quenching temperatures, a relative machine property (hardness), and correlations between ultrasound velocity and attenuation coefficient. Our results can be applied to the examination of heat quenching processes and correspond to the new version of AIAG CQI-9 for metallographic examinations. The following conclusions were drawn.

(1) Ultrasonic wave velocity presented a negative correlation with average grain size - the smaller the grain, 
the faster the wave velocity. The attenuation coefficient showed a positive correlation with average grain size-the larger the grain size, the larger the attenuation. A higher transducer frequency made the effects of scattering more apparent.

(2) Ultrasonic wave velocity revealed a positive correlation with hardness-the greater the hardness, the faster the wave velocity-and better sensitivity occurred at $5 \mathrm{MHz}$ than at $10 \mathrm{MHz}$.

(3) Ultrasound attenuation presented a negative correlation with hardness - the greater the hardness, the lesser the attenuation-and the attenuation coefficient at $10 \mathrm{MHz}$ was $3 \sim 4$ times that at $5 \mathrm{MHz}$ because of high-frequency scattering. With ultrasound attenuation as the measuring datum, better sensitivity appears at $10 \mathrm{MHz}$ than at $5 \mathrm{MHz}$.

(4) Hardness derived from wave velocity measured with a $5 \mathrm{MHz}$ transducer had a $0.75 \%$ difference between the lowest and highest experimental temperatures. Hardness values calculated from the $10 \mathrm{MHz}$ attenuation coefficient were $1.50 \%$ different. Consequently, the attenuation coefficient was used to estimate hardness with an error smaller than the wave velocity.

\section{Conflict of Interests}

The authors declare that there is no conflict of interests regarding the publication of this paper.

\section{References}

[1] S.-Y. Hsia and Y.-T. Chou, "Fabrication improvement of cold forging hexagonal nuts by computational analysis and experiment verification," Mathematical Problem in Engineering, vol. 2014, Article ID 835038, 2014.

[2] S.-Y. Hsia, "Optimization of microextrusion preforming using taguchi method," Mathematical Problems in Engineering, vol. 2013, Article ID 305797, 9 pages, 2013.

[3] W. S. Burkle, "Measurement of ultrasonic longitudinal wave attenuation," Materials Evaluation, vol. 42, no. 3, pp. 262-263, 1984.

[4] B. Kopec and V. Hanak, "Using ultrasonic attenuation measurements to investigate anomalies in the structure of railway axles," NDT International, vol. 17, no. 5, pp. 265-268, 1984.

[5] R. Ambardar, M. T. Muthu, S. D. Pathak, and O. Prabhakar, "Effect of porosity, pore diameter and grain size on ultrasonic attenuation in aluminium alloy castings," Insight: Non-Destructive Testing and Condition Monitoring, vol. 37, no. 7, pp. 536-543, 1995.

[6] R. L. Smith, "The effect of grain size distribution on the frequency dependence of the ultrasonic attenuation in polycrystalline materials," Ultrasonics, vol. 20, no. 5, pp. 211-214, 1982.

[7] D. Nicoletti and A. Anderson, "Determination of grain-size distribution from ultrasonic attenuation: transformation and inversion," Journal of the Acoustical Society of America, vol. 101, no. 2, pp. 686-689, 1997.
[8] L. A. Lott and R. K. Malik, "Ultrasonic inspectability improvements in austenite stainless steel welds after thermal-mechanical processing," Materials Evaluation, vol. 41, no. 6, pp. 738-742, 1983.

[9] W. Wang, S. I. Rokhlin, J. C. Lippold, and L. Adler, "Relationship between ultrasonic measurements and micro-structural characteristics of type 308 stainless steel welds," Materials Evaluation, vol. 47, no. 12, pp. 1388-1395, 1989.

[10] I. H. Sarpun, M. S. Kilickaya, and S. Tuncel, "Mean grain size determination in marbles by ultrasonic velocity techniques," NDT and E International, vol. 38, no. 1, pp. 21-25, 2005.

[11] I. H. Sarpün and M. S. Kiliçkaya, "Mean grain size determination in marbles by ultrasonic first backwall echo height measurements," NDT and E International, vol. 39, no. 1, pp. 8286, 2006.

[12] A. B. Bouda, S. Lebaili, and A. Benchaala, "Grain size influence on ultrasonic velocities and attenuation," NDT \& E International, vol. 36, no. 1, pp. 1-5, 2003.

[13] B. Ahn, S. Seok Lee, S. Taik Hong, H. Chul Kim, and S.J. L. Kang, "Application of the acoustic resonance method to evaluate the grain size of low carbon steels," NDT and E International, vol. 32, no. 2, pp. 85-89, 1999.

[14] W. F. Smith and J. Hashemi, Foundations of Materials Science and Engineering, McGraw-Hill Science, 2009. 

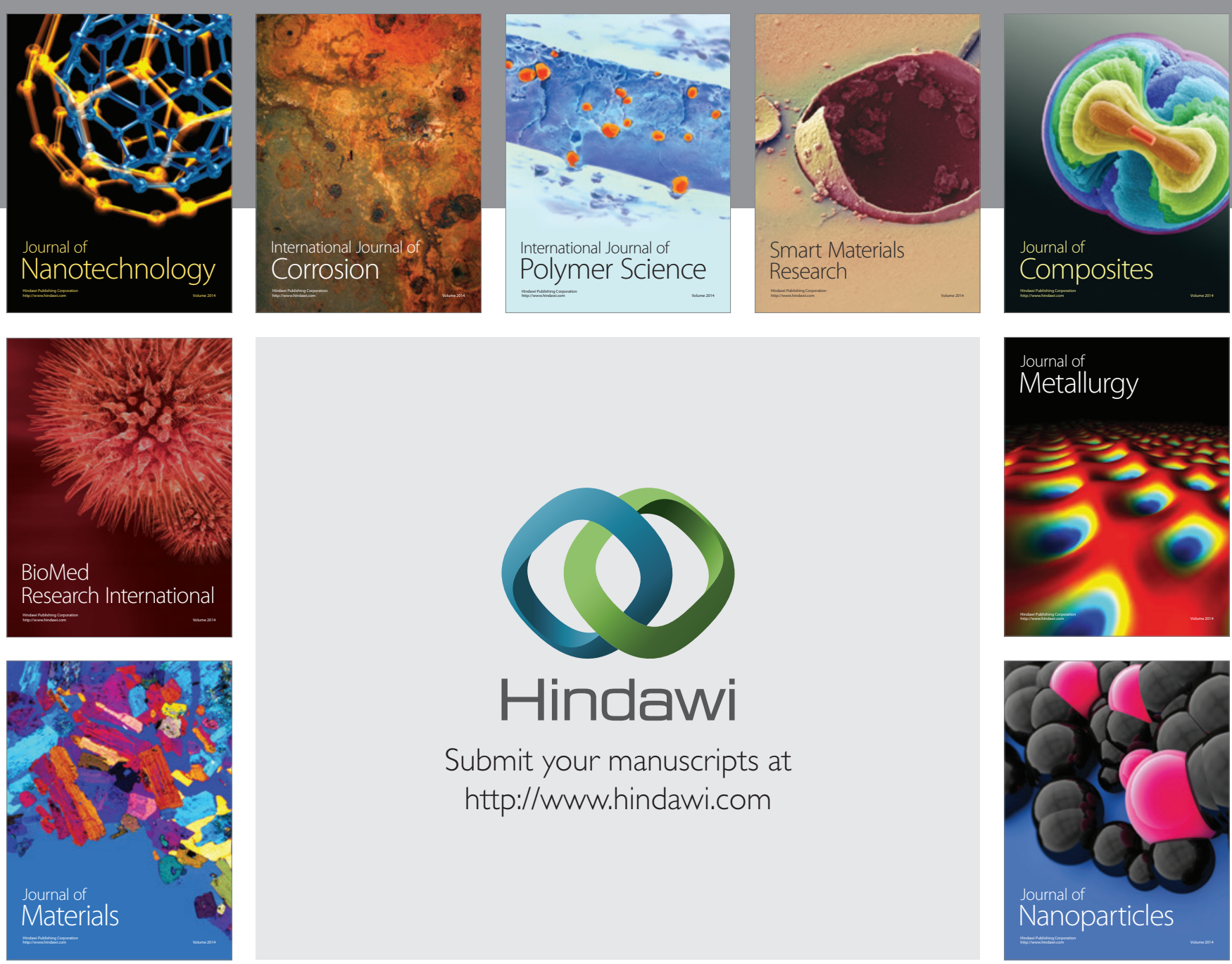

Submit your manuscripts at http://www.hindawi.com
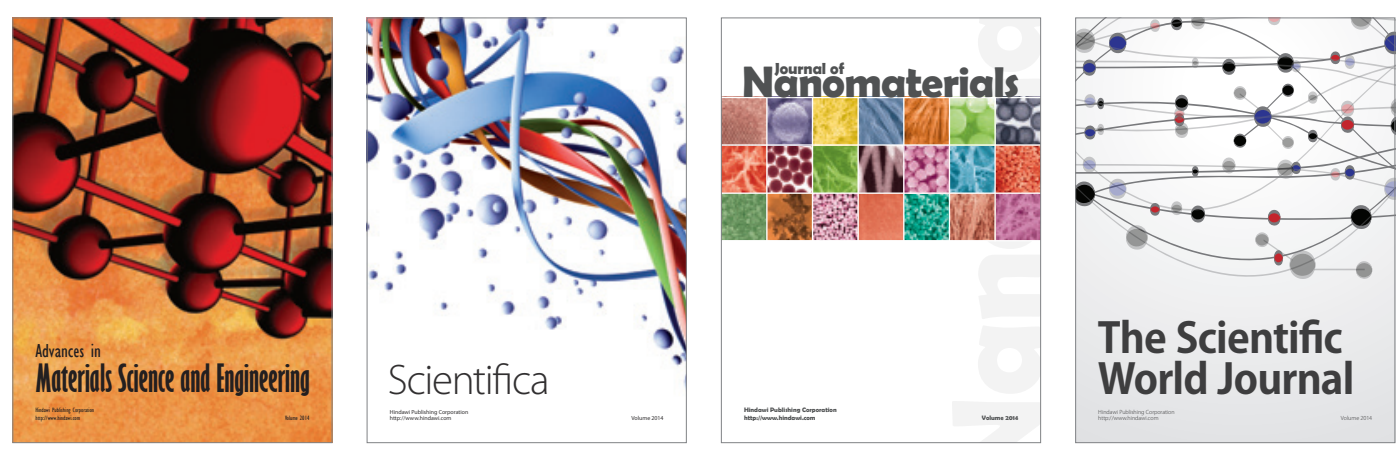

\section{The Scientific World Journal}
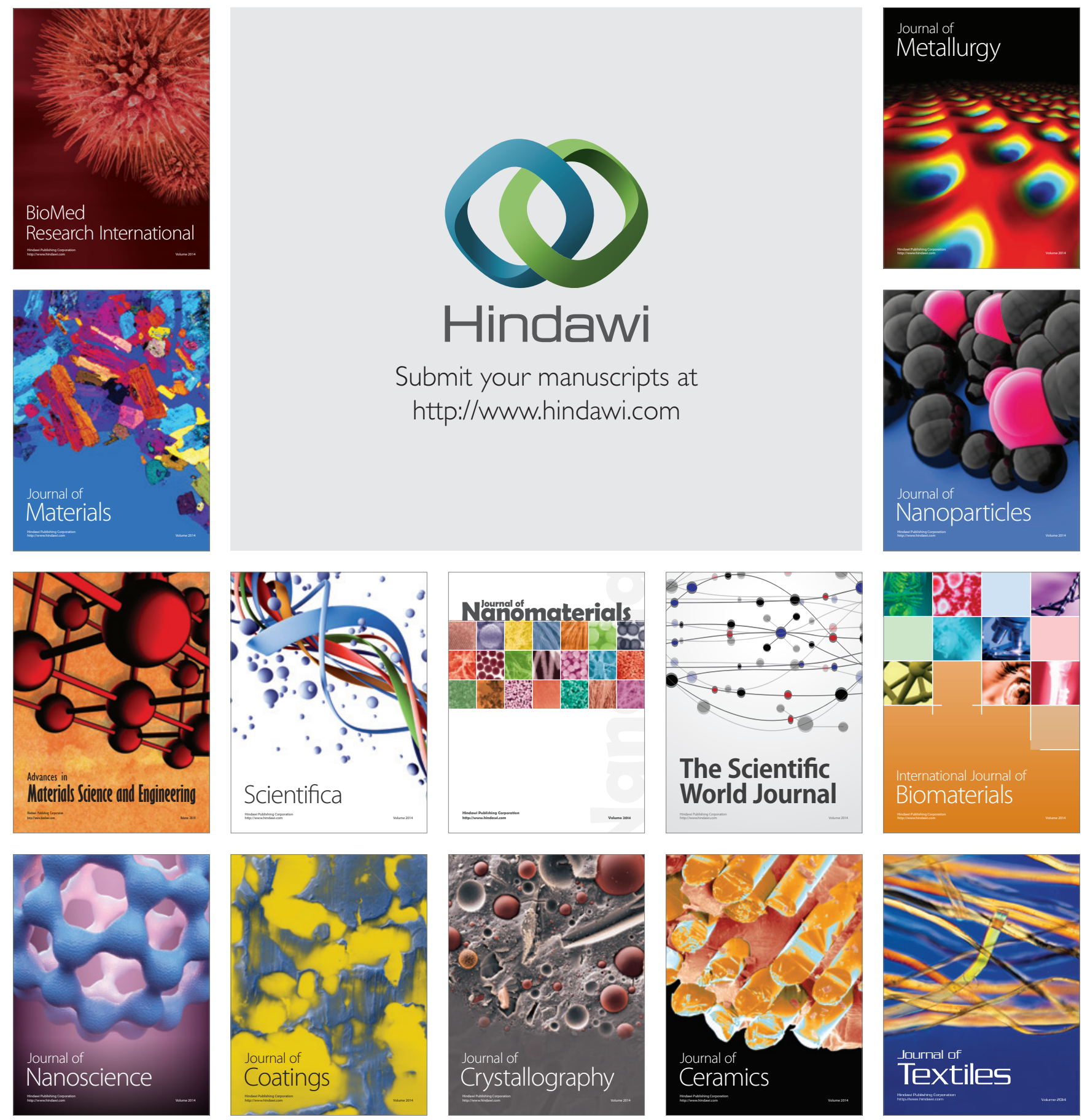